\title{
Subclinical nerve dysfunction in children and adolescents with IDDM
}

\author{
L. Hyllienmark ${ }^{1}$, T. Brismar ${ }^{1}$, J. Ludvigsson ${ }^{2}$ \\ ${ }^{1}$ Department of Clinical Neurophysiology, University Hospital of Linköping, Linköping, Sweden \\ ${ }^{2}$ Department of Paediatrics, University Hospital of Linköping, Linköping, Sweden
}

Summary The purpose of this study was to investigate whether young insulin-dependent diabetic patients still develop peripheral nerve dysfunction when using modern multiple insulin injection therapy and to elucidate if this correlated with various disease parameters. Seventy-five patients, 7 to 20 years old with a duration of diabetes of more than 3 years, and 128 age-matched healthy control subjects underwent bilateral studies of median, peroneal, and sural nerves. Presence of diabetes lowered motor conduction velocity $(p<0.0001)$, sensory conduction velocity $(p<0.0001)$ and sensory nerve action potential $(p<0.05)$ in all examined nerves. The mean change in conduction velocity induced by diabetes was $-4.8 \mathrm{~m} / \mathrm{s}$ in the peroneal nerve, $-3.3 \mathrm{~m} / \mathrm{s}$ in the median motor nerve, $-2.6 \mathrm{~m} / \mathrm{s}$ in the sural nerve and $-2.4 \mathrm{~m} / \mathrm{s}$ in the median sensory nerve. Fifty-seven percent of the patients had abnormal conduction (values outside $95 \%$ predictive interval) which was seen most often in the motor nerves, especially in the peroneal nerve $(41 \%)$ followed by the median nerve $(24 \%)$. In multiple regression analysis, longterm poor metabolic control and increased body length correlated with nerve dysfunction identified in most examined parameters. Three patients had signs or symptoms suggestive of neuropathy. It is concluded that despite modern multiple insulin injection therapy, with reasonably good metabolic control, nerve dysfunction is still common in children and adolescents with insulin-dependent diabetes mellitus. Risk factors are increased height and long-term poor metabolic control. [Diabetologia (1995) 38: 685-692]

Key words Insulin-dependent diabetes mellitus, children, neuropathy, nerve conduction velocity, glycaemic control, height.
Peripheral neuropathy is a common complication of insulin-dependent diabetes mellitus (IDDM) [1], which increases in frequency with the duration of disease [2-4] and is uncommon in children [5]. Although

Received: 3 October 1994 and in revised form: 2 December 1994

Corresponding author: Dr. L. Hyllienmark, Department of Clinical Neurophysiology, University Hospital, S-58185 Linköping, Sweden

Abbreviations: IDDM, Insulin-dependent diabetes mellitus; MIT, multiple insulin injection therapy; MCV, motor nerve conduction velocity; CMAP, compound muscle action potential; DML, distal motor latency; SCV, sensory nerve conduction velocity; SNAP, sensory nerve action potential. unproven, we assume that overt neuropathy with symptoms is preceded by a subclinical form which is important to detect and describe. Electrophysiological studies of nerve conduction velocity are probably our most sensitive tools to quantify early abnormalities [6-8]. Such studies exist in paediatric patients on conventional treatment [9-22] but not in patients on modern multiple insulin injection therapy (MIT). The benefits of using MIT with tight metabolic control on diabetic late complications have been clearly shown [23-26]. The aim of the present study was to ascertain whether young IDDM patients using MIT still develop peripheral nerve dysfunction and to elucidate if this correlated with various disease parameters. 
Table 1. Clinical characteristics of the patients studied and subjects who dropped out of the study

\begin{tabular}{|c|c|c|}
\hline & IDDM patients $(n=75)$ & Dropouts $(n=6)$ \\
\hline Age $(\text { years })^{\mathrm{a}}$ & $15.4 \pm 3.6(7-20)$ & $16.0 \pm 1.4(14-17)$ \\
\hline Height $(\mathrm{cm})^{\mathrm{a}}$ & $164 \pm 17.1(122-197)$ & $167 \pm 8.8(157-183)$ \\
\hline Gender (male/female) & $46 / 29$ & $1 / 5$ \\
\hline Age of onset (years) ${ }^{\mathrm{a}}$ & $7.3 \pm 3.7(1.1-16.1)$ & $7.2 \pm 4.8(1.1-11.7)$ \\
\hline Duration of diabetes (years) ${ }^{\mathrm{a}}$ & $8.2 \pm 3.5(3.3-17.4)$ & $8.8 \pm 5.8(3.2-16.4)$ \\
\hline $\mathrm{HBA}_{1 c} /$ year $(\%)^{\mathrm{a}}$ & $7.0 \pm 1.1(4.8-11.1)$ & $7.4 \pm 0.9(6.6-8.7)$ \\
\hline Anti-GAD positive $(\%)$ & 27 & 33 \\
\hline Fasting C-peptide positive (\%) & 18 & 17 \\
\hline
\end{tabular}

${ }^{a}$ Data are shown as mean \pm SD (range)

\section{Subjects and methods}

Subjects. All 83 IDDM children and adolescents more than 7 years of age attending the Paediatric Clinic, University Hospital, Linköping, Sweden who had a duration of disease of more than 3 years were considered for participation in the study. Two patients were excluded; one 15 -year-old boy with $\mathrm{Mb}$ Down and one 16-year-old girl with severe scleroderma. Six patients did not want to participate in the study which resulted in a final study population of 75 subjects (Table 1 ). Each patient attended once, undergoing the clinical examination and the peripheral nerve tests. All patients were treated with either multiple injection therapy (4-7 daily doses of insulin) or treated with insulin pump.

Laboratory examinations. Capillary blood glucose was measured in 46 patients just before the nerve conduction examination using the hexokinase method with Accutrend mini (Boehringer Mannheim, Mannheim, Germany). Data on glycated haemoglobin $\left(\mathrm{HbA}_{1} / \mathrm{HbA}_{1 \mathrm{c}}\right)$ were collected retrospectively from the medical records for each patient and the mean for each year (about four values) was calculated and then the mean for the whole period of disease (long-term metabolic control). Ion exchange chromatography with a minicolumn method (Quicksep; Isolab, Akron, Ohio, USA) was used to analyse $\mathrm{HbA}_{1}$ in 1980 when the method was introduced. From 1984 an HPLC-method (Auto $\mathrm{A}_{1 \mathrm{c}}$ HA 8110, Boehringer Mannheim) was used, first giving $\mathrm{HbA}_{1}$ and from $1986 \mathrm{HbA}_{1 \mathrm{c}}$. Since 1993 a DCA 2000 is used. The normal range for the $\mathrm{HbA}_{1 \mathrm{c}}$-method in use from 1986-1993 was 3.2$6.0 \%$, and the normal ranges for the other methods correspond well with this interval when transformed [27]. Fasting serum C-peptide [28] was examined in blood collected within a year of the examination. Residual C-peptide was defined as more than $0.05 \mathrm{nmol} / \mathrm{l}$. The physiological range was $0.35-0.85$ nmol/l, mean $0.53 \mathrm{nmol} / 1$ [29]. The duration when the patients had C-peptide secretion was defined as from the time when insulin treatment was started to the time when fasting C-peptide values were below $0.05 \mathrm{nmol} / 1$ in two consecutive measurements. Presence of GAD antibodies (GAD-ab) was evaluated with an immunoprecipitative method [30] and values exceeding $0.055 \mathrm{GAD}$-units were regarded as a positive test.

Neurophysiological examinations. Studies were performed with a standard technique using surface electrodes [31]. Motor nerve conduction velocity (MCV), compound muscle action potential (CMAP) and distal motor latency (DML) were determined bilaterally in the median and peroneal nerves. Sensory nerve conduction velocity (SCV) and sensory nerve action potential (SNAP) amplitude were deter- mined bilaterally in the median and sural nerves. Complete nerve conduction studies were performed in all diabetic subjects except two who were examined in both arms but only in one leg. In one patient the data from one arm were discarded, since he was in the recovery phase after breaking that arm. The examination was performed in a warm room $\left(21-23^{\circ} \mathrm{C}\right)$. The arms and legs of all patients were warmed with heat pads for at least 10 min prior to the nerve conduction measurements, in order to obtain skin temperatures around $34^{\circ} \mathrm{C}$. All patients were examined by the same experienced technician.

Clinical evaluation and examination. A standard direct inquiry was made for heredity of neurological disease, presence of disease known to influence peripheral nerve function and typical symptoms of neuropathy modfied after Dyck et al. [32]. The tendon reflexes were examined in quadriceps and gastrocnemius bilaterally, and if absent also in biceps, triceps and brachioradialis bilaterally, and the vibration sense was tested in the big toe bilaterally with a $128 \mathrm{~Hz}$ tuning fork. These tests were all made by one of the authors (LH). The study was done according to the Helsinki Declaration of 1975, and approved by the Ethical Committee, Faculty of Health Sciences, Linköp.

\section{Statistical analysis}

Multiple regression analysis with height $(\mathrm{H})$ and limb temperature was used to test the influence of diabetes on MCV, SCV, CMAP, SNAP and DML. Individual values were defined as abnormal when they were outside the calculated $95 \%$ predicted intervals ( $=2 \mathrm{SD}$ ) in the data from the control subjects. All nerve conduction data are described in relation to the height of the diabetic patients and the control subjects. Conduction parameters in healthy children and adolescents are calculated using the following formulae: median $\mathrm{MCV}=$ $52.6+0.043 \times \mathrm{H}$, peroneal $\mathrm{MCV}=62.1-0.065 \times \mathrm{H}$, median $\mathrm{SCV}=46.9+0.073 \times \mathrm{H}$, sural $\mathrm{SCV}=55.5+0.004 \times \mathrm{H}, \log _{10}$ $($ median SNAP $)=1.40+8.0 \times 10^{-5} \times \mathrm{H}, \log _{10}($ sural $\mathrm{SNAP})=$ $1.66-3.5 \times 10^{-3} \times \mathrm{H}$ and median $\mathrm{DML}=1.26+9.5 \times 10^{-3} \times \mathrm{H}$. The value of each conduction parameter in each diabetic patient minus the correspondlng value in control subjects of the same height was taken as a measure of nerve dysfunction and was tested against disease parameters using correlation analysis and multiple regression. Effects were judged to be non-significant when $p>0.05$. 

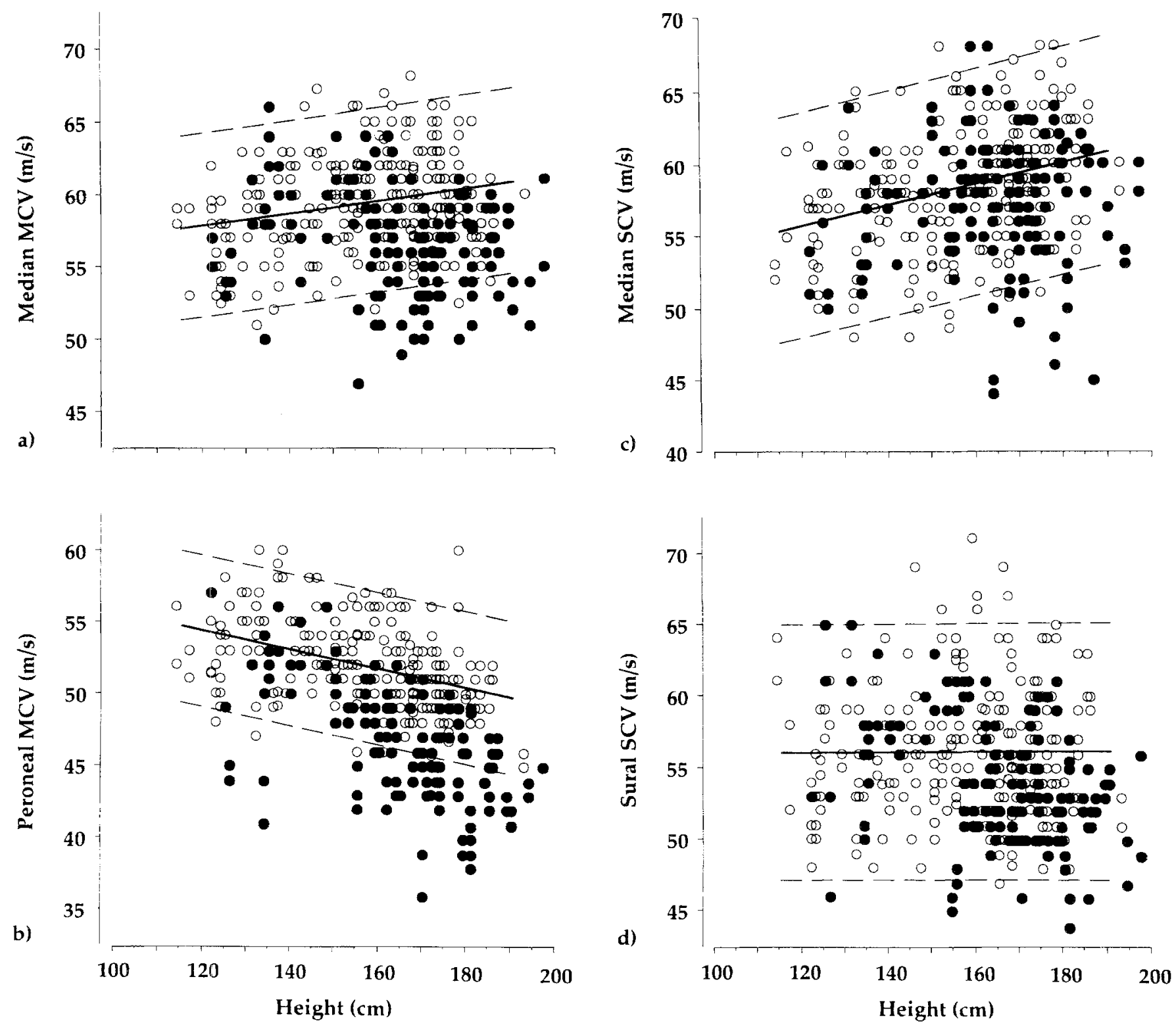

Fig.1a-d Effect of diabetes on motor (MCV) and sensory nerve conduction velocity (SCV) as a function of height in 400 nerves from 203 children and adolescents ( $O$ healthy control subjects, IDDM patients). Solid line shows data

\section{Results}

Clinical evaluation and glycaemic control. No patient had a history of neurological or metabolic disease besides diabetes, of alcohol abuse or was taking any medicine known to influence peripheral nerve function. One diabetic woman, 20 years old smoked more than 5 cigarettes per day. Two patients reported possible symptoms associated with neuropathy. One boy, age 15 , reported reduced sensation in the fingertips occasionally, and another boy, age 14 complained of his hands falling asleep now and then. Tendon reflexes were present in all but one patient (a 20-year-old male) who had absent bilateral reflexes in the gastrocnemius, quadriceps and biceps

from healthy control subjects using linear regression (equation given in Methods) and the broken lines show $95 \%$ predictive intervals. (a) median MCV, (b) peroneal MCV, (c) median $\mathrm{SCV}$, (d) sural SCV

brachii muscles. He had had diabetes for 17 years, his mean $\mathrm{HbA}_{1 \mathrm{c}}$ was $9.3 \%$. No patient had ketonuria within the last 14 days prior to examination and none was in a period of extremely poor metabolic control according to recent $\mathrm{HbA}_{1 \mathrm{c}}$ values, measuring $7.2 \pm 1.2(\mathrm{SD}) \%$ with a range $4.7-10.3 \%$.

Effect of diabetes on nerve conduction. Presence of diabetes lowered MCV $(p<0.0001), \quad$ SCV $(p<0.0001)$ and SNAP $(p<0.05)$ in each examined nerve and DML in the median nerve was prolonged $(p<0.05)$ (Fig. 1a-d). DML in the peroneal nerve and CMAP in the median and peroneal nerves were not influenced by the presence of diabetes. The mean value of the change induced by diabetes was 
Table 2. Skin temperatures over nerve segment $\left({ }^{\circ} \mathrm{C}\right)$

\begin{tabular}{lll}
\hline Nerve & $\begin{array}{l}\text { IDDM patients } \\
(n=148)\end{array}$ & $\begin{array}{l}\text { Control subjects } \\
(n=254)\end{array}$ \\
\hline Median MCV & $33.6 \pm 1.1(31.0-36.5)$ & $33.3 \pm 1.1(30.3-36.3)$ \\
Peroneal MCV & $33.5 \pm 1.2(31.0-36.3)$ & $33.2 \pm 1.2(30.5-36.7)$ \\
Median SCV $^{\mathrm{a}}$ & $34.3 \pm 0.92(32.0-36.5)$ & $33.7 \pm 1.1(31.1-36.6)$ \\
Sural SCV & $34.0 \pm 1.3(31.8-37.0)$ & $33.6 \pm 1.3(30.5-36.5)$ \\
\hline
\end{tabular}

${ }^{a}$ Data are shown as mean \pm SD (range)

$-3.3 \mathrm{~m} / \mathrm{s}$ in median $\mathrm{MCV},-4.8 \mathrm{~m} / \mathrm{s}$ in peroneal $\mathrm{MCV}$, $-2.4 \mathrm{~m} / \mathrm{s}$ in median $\mathrm{SCV},-2.6 \mathrm{~m} / \mathrm{s}$ in sural $\mathrm{SCV}$, $-2.4 \mu \mathrm{V}$ in median SNAP, $-1.5 \mu \mathrm{V}$ in sural SNAP and $0.08 \mathrm{~ms}$ in median DML. The skin temperature was slightly higher in the patients than in the control subjects (Table 2). Measurements in the control group have shown that higher skin temperature is related to higher conduction velocity (unpublished data) but the data shown in Figure 1 have not been adjusted for temperature differences.

In $32(43 \%)$ out of 75 examined patients MCV, SCV, SNAP in all examined nerves and median DML bilaterally were within the normal range. Only one abnormal parameter (on right or left side, or bilaterally) was detected in $14(19 \%)$ patients. Two parameters were abnormal in $17(23 \%)$ patients, three parameters were abnormal in six $(8 \%)$, four parameters in four $(5 \%)$, and five parameters were abnormal in two patients. No patient had abnormal values in more than five parameters. The peroneal MCV was most frequently affected, showing abnormal values in $61(41 \%)$ out of 148 examined nerves. The percentages of abnormal parameters were $24 \%$ in median MCV, $7 \%$ in median SCV, $6 \%$ in sural SCV, $5 \%$ in each of median DML, median SNAP and sural SNAP. Thirty-three (44\%) of the 75 patients had abnormal peroneal MCV on at least one side, and in $32 \%$ median MCV was abnormal, in $15 \%$ median SCV, in $9 \%$ median SNAP, in $8 \%$ sural $\mathrm{SCV}$, in $8 \%$ sural SNAP and in $7 \%$ of the patients median DML was abnormal on at least one side.

Effect of metabolic control. Table 3 shows how nerve dysfunction defined as height compensated deviation from the reference value (see Methods) correlated to different parameters. Long-term poor metabolic control correlated with nerve dysfunction identified in the peroneal $\mathrm{MCV}(p<0.0001)$ (Fig. 2), median MCV $(p<0.05)$, median SCV $(p<0.05)$, sural SCV $(p<0.05)$, median SNAP $(p<0.05)$ and sural SNAP $(p<0.05)$. Poor metabolic control during the last year (mean of about four values of $\mathrm{HbA}_{1 \mathrm{c}}$ ) correlated with dysfunction of the median and peroneal $\mathrm{MCV}$, although not as strongly as the long-term poor metabolic control. Metabolic control during the last months (present $\mathrm{HbA}_{1 \mathrm{c}}$ value) correlated with dysfunction in the peroneal and median MCV and median and sural SNAP. For sural SNAP this correlation was stronger than with the long-term poor metabolic control. Blood glucose measured in connection with the nerve conduction examination was $9.1 \mathrm{mmol} / 1$ (mean, range $4.0-17.8 \mathrm{mmol} / \mathrm{l}$ ). High blood glucose at examination correlated with nerve dysfunction identified in the peroneal MCV $(p<0.001)$ (Fig. 3), sural SNAP $(p<0.001)$, median MCV $(p<0.05)$, median SCV $(p<0.05)$, median SNAP $(p<0.05)$ and sural SCV $(p<0.05)$. Dysfunction identified in median SNAP, sural SCV and sural SNAP correlated more with high blood glucose at examination than with long-term poor metabolic control.

Influence of height, age, age of onset, diabetes duration, and C-peptide. Although the normal influence of height on nerve conduction has been considered it is evident in Figure 1 that nerve dysfunction was more common in tall children and adolescents. Table 3 shows that increased height of the patient correlated with nerve dysfunction in median $\mathrm{MCV}$ $(p<0.0001)$, peroneal MCV $(p<0.0001)$, sural SCV $(p<0.0001)$, median SCV $(p<0.05)$, median SNAP $(p<0.05)$ and sural SNAP $(p<0.05)$. Nerve dysfunction was also correlated to the age of the patient in three of the measured conduction parameters (median MCV, peroneal MCV and sural SCV). However, these correlations were not as pronounced as for height (see Table 3). Dysfunction in median and peroneal MCV was correlated to older age of onset $(p<0.05)$. Duration of disease was only correlated

Table 3. Correlation $(r)$ between nerve dysfunction and patient parameters

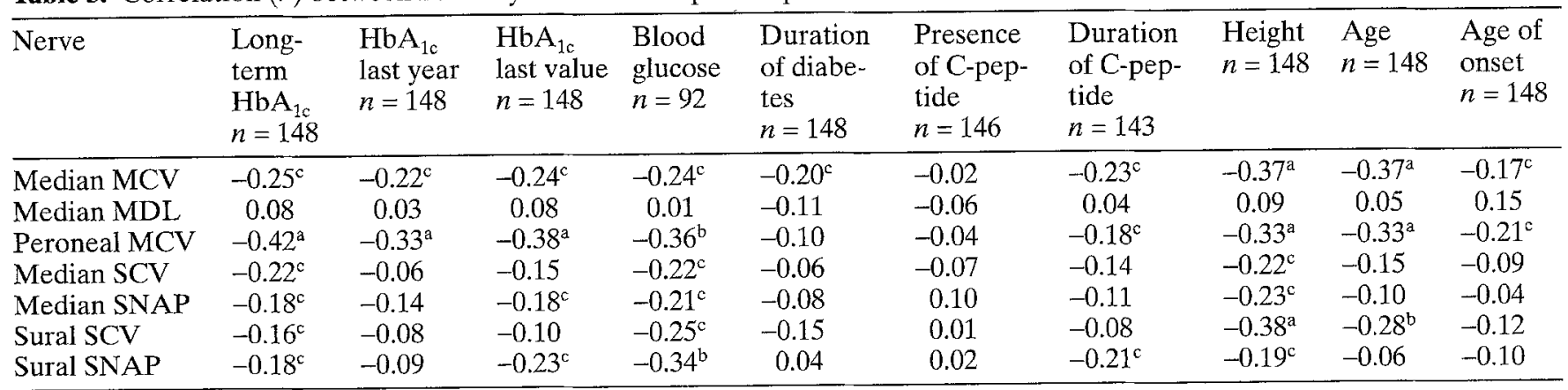

${ }^{\mathrm{a}} p<0.0001 ;{ }^{\mathrm{b}} p<0.001 ;{ }^{\mathrm{c}} p<0.05$ 


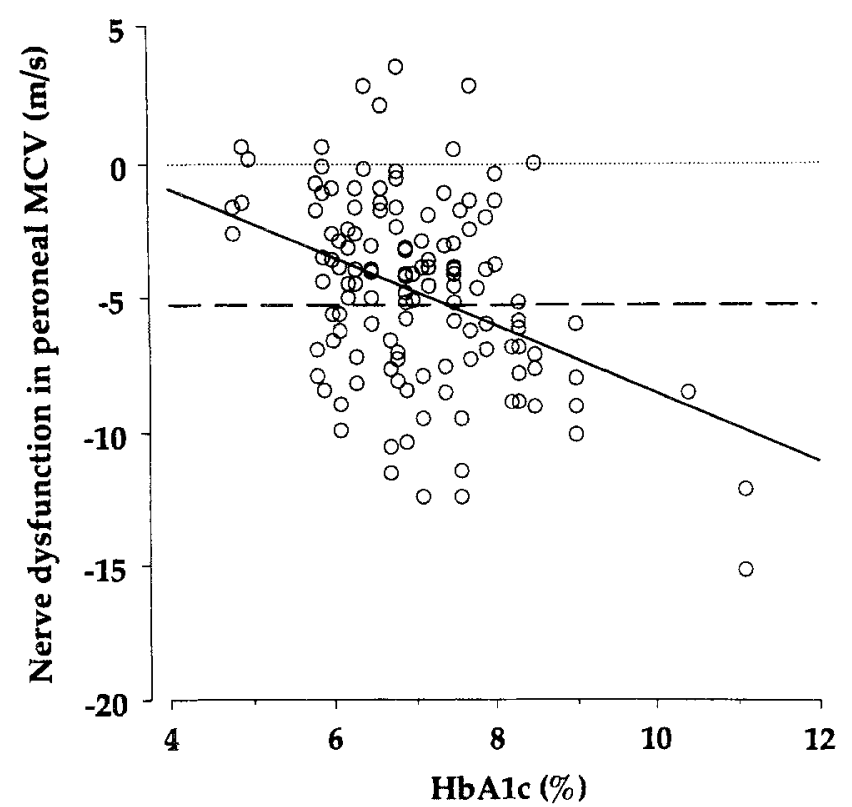

Fig. 2 Nerve dysfunction identified in peroneal MCV as a function of long-term metabolic control (defined in Methods) in 148 nerves from 75 patients with IDDM. Solid line obtained from linear regression analysis according to equation $y=4.2-$ $1.3 x, r=0.42$. Dotted line shows expected value from healthy control subjects and dashed line lower limit for $95 \%$ predictive interval

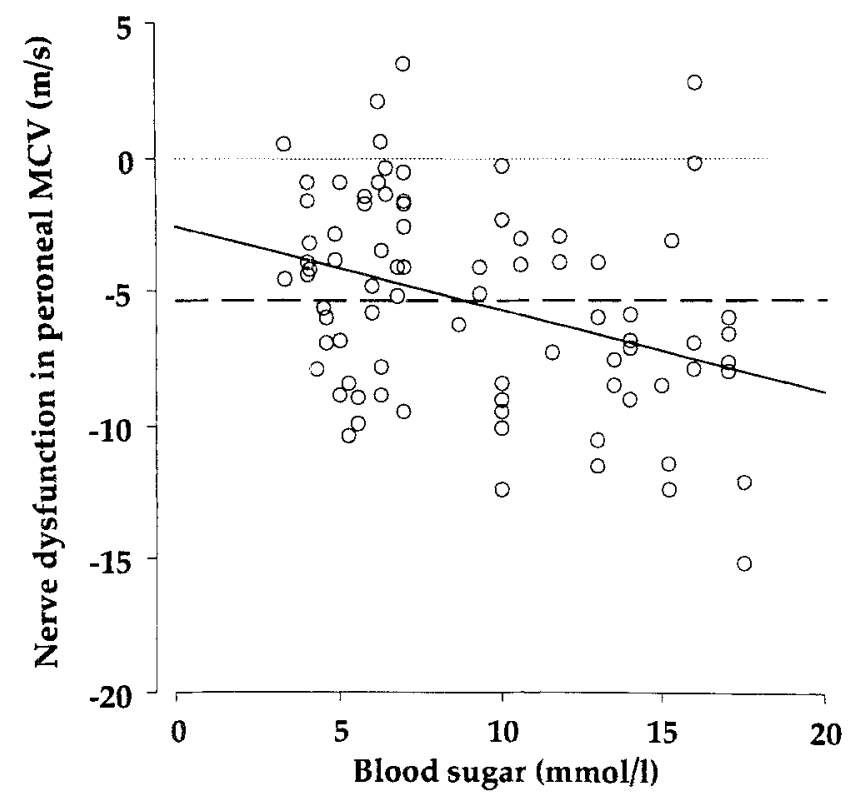

Fig.3 Nerve dysfunction identified in peroneal MCV as a function of blood-glucose at examination in 92 nerves from $46 \mathrm{pa}$ tients with IDDM. Solid line obtained from linear regression analysis according to equation $y=-2.6-0.31 x, r=0.36$. Dotted line shows expected value from healthy control subjects and dashed line lower limit for $95 \%$ predictive interval

with decrease in median MCV $(p<0.05)$. Neither presence of GAD-ab nor the sex of the subject correlated with nerve dysfunction.

Detectable levels of C-peptide were found in 67 of 72 patients at diagnosis (mean $0.19 \mathrm{nmol} / \mathrm{l}$, range

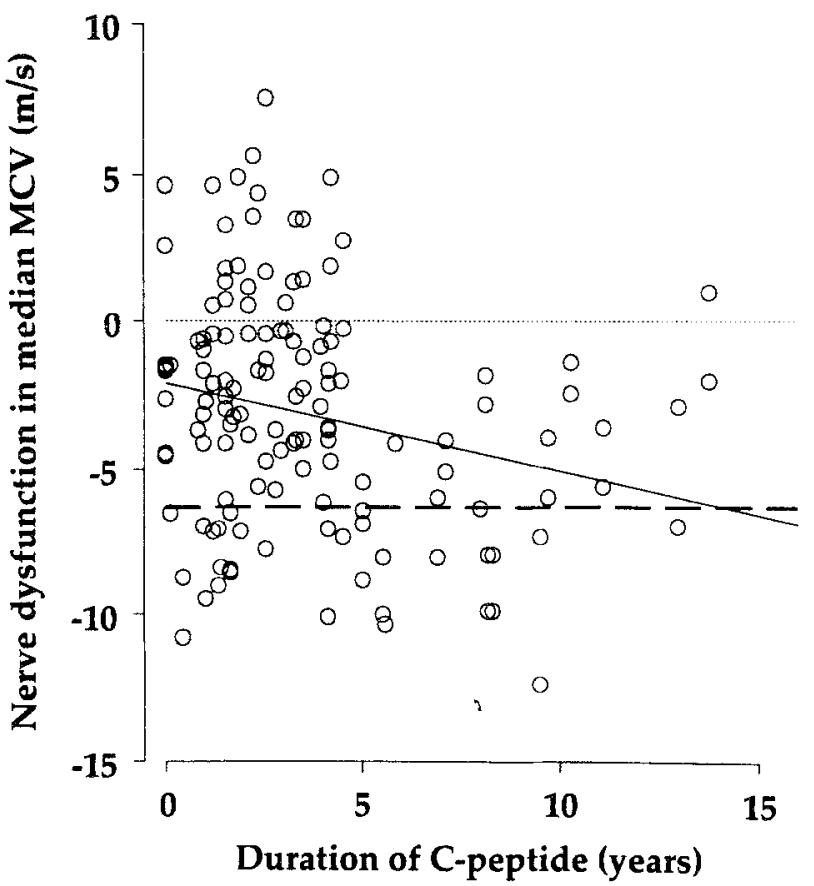

Fig. 4 Nerve dysfunction identified in median MCV as a function of duration of C-peptide in 143 nerves from 72 patients with IDDM. Solid line obtained from linear regression analysis according to equation $y=-2.1-0.30 x, r=0.23$. Dotted line shows expected value from healthy control subjects and dashed line lower limit for $95 \%$ predictive interval

$0.02-0.63 \mathrm{nmol} / \mathrm{l})$ and after $2-3$ years diabetes duration in 26 of 72 patients. At the neurophysiological examination 13 of 73 patients had detectable levels of circulating C-peptide. Five patients had levels from $0.06-0.11 \mathrm{nmol} / 1,6$ patients had levels of $0.12-$ $0.34 \mathrm{nmol} / \mathrm{l}$ and only two patients had values within the physiological range. Neither presence of remaining C-peptide secretion nor number of years without $\mathrm{C}$-peptide secretion correlated with nerve function. However, there was a weak correlation $(p<0.05)$ between nerve dysfunction identified in median and peroneal MCV and sural SNAP and the number of years with detectable C-peptide secretion (Fig.4). This was further analysed in the multiple regression.

Multiple regression. In order to perform a multiple regression analysis any possible correlation between long-term $\mathrm{HbA}_{1 \mathrm{c}}$, blood-glucose at examination, height, number of years with C-peptide secretion, duration of disease and age of onset was examined. Both age of onset and duration of disease correlated to height $(p<0.0001)$ so they were not included in the multiple regression analysis. Of the remaining parameters there was a correlation between high blood glucose at examination and long-term poor metabolic control $(r=0.37, p<0.0001)$. Blood glucose at examination was only examined in $60 \%$ of the patients and therefore it was excluded in the further analysis. Height and number of years with C- 
peptide secretion did not correlate to each other or to long-term poor metabolic control so they were included in the multiple regression analysis. Increased height had a stronger negative effect on nerve function than long-term poor metabolic control in median MCV and SCV, sural SCV and SNAP and median SNAP. Long-term poor metabolic control had a stronger effect only in peroneal MCV. Number of years with C-peptide secretion was still associated with nerve dysfunction in median MCV and sural SNAP $(p<0.05)$ but not in peroneal MCV. An indication of the strength of the regression model are the $r^{2}$ values which were: 0.28 for peroneal $\mathrm{MCV}$, 0.22 for median MCV, 0.17 for sural SCV, 0.10 for median SCV and sural SNAP, and 0.08 for median SNAP.

Correlation between nerve conduction parameters. Dysfunction of peroneal MCV indicated dysfunction also in the other parameters of nerve conduction. Peroneal MCV correlated with median MCV $(r=0.60, \quad p<0.0001), \quad$ median SCV $(r=0.30$, $p<0.001)$, sural SCV $(r=0.46, p<0.0001)$, sural SNAP $(r=0.19, p<0.05)$, median DML $(r=-0.22$, $p<0.05)$ and median SNAP $(r=0.16 \mathrm{NS})$.

\section{Discussion}

The most important findings of this study are (1) that despite modern MIT-treatment with reasonably good metabolic control nerve dysfunction is still common in an unselected group of children and adolescents with IDDM (2) that a decrease in conduction velocity is more common in motor than in sensory nerves, and (3) that poor metabolic control and high body length are independent risk factors for nerve dysfunction. It is noteworthy that only 3 of the 75 patients had any signs or symptoms of neuropathy.

A decrease in both MCV and SCV has previously been demonstrated in children and adolescents with IDDM [14, 16, 21]. However, this is the first study in which all patients have received MIT-treatment. Since in Sweden all children and adolescents with diabetes within a geographic region attend the same hospital clinic this material is unselected. There were very few drop-outs, and their clinical data did not differ from those of the remaining group. Therefore, our results are based on a representative population of children and adolescents with IDDM.

Abnormality was most clearly seen in the peroneal nerves where the decrease in MCV was largest and most common, followed by a decrease in median MCV. Sensory nerve conduction (SCV and SNAP) was less often affected. This distribution is similar to the one found in adult patients with diabetic neuropathy $[8,33,34]$ and in children with IDDM $[16,21]$. Earlier studies in adults with overt diabetic neuropa- thy have suggested that sensory nerve fibres are affected before motor fibres $[33,35]$. However, this is not corroborated by our results indicating that in large myelinated fibres which are studied with the present neurographic techniques, motor fibres are affected before sensory fibres. Since the present study was performed in young IDDM patients before neuropathic symptoms have evolved, it should give a better picture of the early stages of nerve dysfunction in these fibre types.

An association between decreased MCV or SCV and poor metabolic control in young patients with IDDM has been demonstrated in several investigations $[14,16,17,21,36,37]$. In the present study we have distinguished the influence of long-term poor metabolic control, and found nerve dysfunction to correlate more to this factor than to the most recent $\mathrm{HbA}_{1 \mathrm{c}}$-values. Of special interest was the finding that high blood glucose at examination showed such a strong correlation to nerve dysfunction. The correlation coefficients $(r)$ were actually higher than the corresponding values for long-term poor metabolic control in median and sural SNAP and sural SCV. It is at present difficult to draw any conclusion from this finding because of the high correlation between high blood glucose at examination and long-term poor metabolic control. Since it has been shown that MCV can improve after improved metabolic control, both in adults [38] and adolescents [39, 40], it may be that neuropathy is prevented by the introduction of MIT [25]. Our findings in MIT-treated patients with a mean diabetes duration of 8.2 years indicate that very low mean $\mathrm{HbA}_{1 \mathrm{c}}$-values (about $6 \%$ ) are required to prevent nerve dysfunction. On the other hand, mean $\mathrm{HbA}_{1 \mathrm{c}}$-values over $9 \%$ we invariably related to nerve dysfunction.

Height seems to be an independent risk factor for development of neuropathy in both young $[21,41]$ and adult IDDM patients [42-44]. It is difficult to discern height as a risk factor since the normal values of nerve conduction change with height and since there is a correlation between height and other parameters such as duration of disease and age of onset. Our height compensated data confirmed that increased height is an independent risk factor. Height compensation may explain why we did not find gender to be a risk factor which contrasts with earlier studies [21, 44]. The negative effect of height on nerve function may be related to the increase in length of the nerve fibres, since in diabetic polyneuropathy nerve fibers lose function according to their length [45] and the deficits begin, and are more intense distally [45-47]. One possible mechanism for this may be an impairment of axonal transport demonstrated in streptozotocin-diabetic rats [48].

The possible effect of C-peptide on nerve function was examined in several ways (presence of circulating $\mathrm{C}$-peptide, duration with and without C-peptide). We 
did not find any beneficial effects and could not confirm previous reports $[13,43]$. It should be noted that only two patients had circulating C-peptide levels within the physiological range and the levels in most of the patients may have been too low to be effective. Late age of diabetes onset correlated to nerve dysfunction, but since age of onset correlated strongly to height we believe that increased height explains this finding. As shown earlier both in peripheral somatic [49] and autonomic nerves [50] absence of GAD-ab does not prevent nerve dysfunction.

From this study we conclude that despite modern MIT-treatment with good metabolic control nerve dysfunction is still common in an unselected material of children and adolescents with IDDM. The most important risk factors were increased height and long-term poor metabolic control whereas duration of diabetes plays a less important role than earlier reported $[10-12,14-16,41]$.

Acknowledgements. Supported by grants from the Swedish Child Diabetes Foundation (Barndiabetesfonden) and the Swedish Medical Research Council (project no. 14x-4255). We thank technician Ms. G. Lundblad for skillful assistance with nerve function tests.

\section{References}

1. Dyck PJ, Kratz KM, Karnes JL et al. (1993) The prevalence by staged severity of various types of diabetic neuropathy, retinopathy, and nephropathy in a population-based cohort: the Rochester diabetic neuropathy study. Neurology 43: $817-824$

2. Pirart J (1978) Diabetes mellitus and its degenerative complications. a prospective study of 4,400 patients observed between 1947 and 1973. Diabetes Care 1: 168-188

3. Orchard TJ, Dorman JS, Maser RE et al. (1990) Prevalence of complications in IDDM by sex and duration. Diabetes 39: $1116-1124$

4. Young MJ, Boulton AJM, MacLeod AF, Williams DRR, Sonksen PH (1993) A multicentre study of the prevalence of diabetic peripheral neuropathy in the United Kingdom hospital clinic population. Diabetologia 36: 150 154

5. Thomas PK, Tomlinson DR (1993) Diabetic and hypoglycaemic neuropathy. In: Dyck PJ, Thomas PK. Griffin JW, Low PA, Poduslo JF (eds) Peripheral neuropathy, vol 2 (3rd edn). Saunders, Philadelphia London Toronto Montreal Sydney Tokyo, pp 1219-1250

6. Schaumburg HH, Spencer PS, Thomas PK (1983) Disorders of peripheral nerves. Contemporary Neurology Series no 24, FA Davis Company, Philadelphia, pp 41-55

7. Abraham R, Levy D (1990) Diabetic neuropathy: measurement and quantification. In: Ward J, Goto Y (eds) Diabetic neuropathy. Wiley, Chichester New York Brisbane Toronto Singapore, pp 259-268

8. Claus D, Mustafa C, Vogel W, Herz M, Neundörfer B (1993) Assessment of diabetic neuropathy: definition of norm and discrimination of abnormal nerve function. Muscle Nerve 16: 757-768

9. Lawrence DG, Locke S (1963) Neuropathy in children with diabetes mellitus. BMJ 1: 784-785
10. Gamstorp I, Shelburne SA, Engleson G, Redondo D, Traisman HS (1966) Peripheral neuropathy in juvenile diabetes. Diabetes $15: 411-418$

11. Eeg-Olofsson O, Petersen I (1966) Childhood diabetic neuropathy a clinical and electrophysiological study. Acta Paediatrica 55: 163-176

12. Marcus J, Ehrlich R, Kelly M, Murphy EG (1973) Nerve conduction in childhood diabetes. Can Med Assoc J 108: 1116-1119

13. Ludvigsson J, Johannesson G, Heding L, Häger A, Larsson Y (1979) Sensory nerve conduction velocity and vibratory sensibility in juvenile diabetics. Relationships to endogenous insulin. Acta Paediatrica 68: 739-743

14. Young RJ, Ewing DJ, Clarke BF (1983) Nerve function and metabolic control in teenage diabetics. Diabetes 32: 142147

15. Hoffman WH, Hart ZH, Frank RN (1983) Correlates of delayed motor nerve conduction and retinopathy in juvenile-onset diabetes mellitus. J Pediatr 102: 351-356

16. Kär ML, Saukkonen AL, Pitkänen M, Åkerblom HK (1983) Peripheral neuropathy in diabetic children and adolescents. A cross-sectional study. Acta Paediatrica 72: 373378

17. Dorchy H, Noel P, Kruger M et al. (1985) Peroneal motor nerve conduction velocity in diabetic children and adolescents. Eur J Pediatr 144: 310-315

18. Young RJ, Macintyre CCA, Martyn CN et al. (1986) Progression of subclinical polyneuropathy in young patients with type 1 (insulin-dependent) diabetes: associations with glycaemic control and microangiopathy (microvascular complications). Diabetologia 29: 156-161

19. Kruger M, Brunko E, Dorchy H, Noël P (1987) Femoral versus peroneal neuropathy in diabetic children and adolescents - relationships to clinical status, metabolic control and retinopathy. Diabete Metab 13: 110-115

20. Gallai V, Firenze C, Mazzotta G, Del Gatto F (1988) Neuropathy in children and adolescents with diabetes mellitus. Acta Neurol Scand 78: 136-140

21. Duck SC, Wei F, Parke J, Swick HM (1991) Role of height and glycosylated haemoglobin in abnormal nerve conduction in paediatric patients with type I diabetes mellitus after 4-9 yr of disease. Diabetes Care 14: 386-392

22. Allen C, Duck SC, Sufit RL, Swick HM, D'Alessio DJ (1992) Glycaemic control and peripheral nerve conduction in children and young adults after 5-6 months of IDDM. Diabetes Care 15: 502-507

23. Amthor K-F, Dahl-Jørgensen K, Berg TJ et al. (1994) The effect of strict glycaemic control on peripheral nerve function in IDDM patients: the Oslo study. Diabetologia 37 : 579-584

24. Bojestig M, Arnqvist HJ, Hermansson G, Karlberg BE, Ludvigsson J (1994) Declining incidence of nephropathy in insulin-dependent diabetes mellitus. N Engl J Med 330: $15-18$

25. The Diabetes Control and Complications Trial Research Group (1994) The effect of intensive treatment of diabetes on the development and progression of long-term complications in insulin-dependent diabetes mellitus. N Engl J Med 329: 977-986

26. Reichard P, Nilsson B-Y, Rosenqvist U (1994) The effect of long-term intensified insulin treatment on the development of microvascular complications of diabetes mellitus. N Engl J Med 329: 304-309

27. Kullberg CE, Arnqvist HJ (1993) Elevated long-term glycated haemoglobin precedes proliferative retinopathy and nephropathy in type 1 (insulin-dependent) diabetic patients. Diabetologia 36: 961-965 
28. Heding LG (1975) Radioimmunological determination of human C-peptide in serum. Diabetologia 11: 541-548

29. Johansson B-L (1992) Physiological effects of C-peptide administration in patients with type 1 diabetes. Thesis, Karolinska Institute, Stockholm

30. Grubin CE, Daniels T, Toivola B et al. (1994) A novel radioligand binding assay to determine diagnostic accuracy of isoform-specific glutamic acid decarboxylase antibodies in childhood IDDM. Diabetologia 37: 344-350

31. Ludin HP (1980) Electromyography in practice. Thieme, Stuttgart

32. Dyck PJ, Karnes J, O'Brien PC, Swanson CJ (1986) Neuropathy symptom profile in health, motor neuron disease, diabetic neuropathy, and amyloidosis. Neurology 36: 13001308

33. Lamontagne A, Buchtal F (1970) Electrophysiological studies in diabetic neuropathy. J Neurol Neurosurg Psychiatry 33: 442-452

34. Dyck PJ, Karnes JL, Daube J, O’Brien P, Service FJ (1985) Clinical and neuropathological criteria for the diagnosis and staging of diabetic polyneuropathy. Brain 108: 861-880

35. Buchtal F, Rosenfalck A (1971) Sensory potentials in polyneuropathy. Brain 94: 241-262

36. Gregersen G (1967) Diabetic neuropathy: influence of age, sex, metabolic control, and duration of diabetes on motor conduction velocity. Neurology 17: 972-980

37. Ziegler D, Mayer P, Mühlen H, Gries FA (1991) The natural history of somatosensory and autonomic nerve dysfunction in relation to glycaemic control during the first 5 years after diagnosis of Type 1 (insulin-dependent) diabetes mellitus. Diabetologia 34: 822-829

38. Pietri A, Ehle AL, Raskin P (1980) Changes in nerve conduction velocity after six weeks of glucoregulation with portable insulin infusion pump. Diabetes 29: 668-671

49. White NH, Waltman SR, Krupin T, Santiago JV (1981) Reversal of neuropathic and gastrointestinal complications related to diabetes mellitus in adolescents with improved metabolic control. J Pediatr 99: 41-45

40. Service FJ, Rizza RA, Daube JR, O'Brien PC, Dyck PJ (1985) Near normoglycaemia improved nerve conduction and vibration sensation in diabetic neuropathy. Diabetologia 28 : 722-727
41. The Diabetes Control and Complications Trial Research Group (1988) Factors in development of diabetic neuropathy. Baseline analysis of neuropathy in feasibility phase of diabetes control and complication trial (DCCT). Diabetes 37: 476-481

42. Sosenko JM, Gadia MT, Fournier AM, O'Connell MT, Aguiar MC, Skyler JS (1986) Body stature as a risk factor for diabetic sensory neuropathy. Am J Med 80: 1031-1034

43. Gadia MT, Natori N, Ramos LB, Ayyar DR, Skyler JS, Sosenko JM (1987) Influence of height on quantitative sensory, nerve-conduction, and clinical indices of diabetic peripheral neuropathy. Diabetes Care 10: 613-616

44. Robinson LR, Stolow WC, Rubner DE, Wahl PW, Leonetti DL, Fujimoto WY (1992) Height is an independent risk factor for neuropathy in diabetic men. Diabetes Res Clin Pract 16: 97-102

45. Sabin TD, Geschwind N, Waxman SG (1978) Patterns of clinical deficits in peripheral nerve disease. In: Waxman SG (ed) Physiology and pathobiology of axons. Raven Press, New York, pp 431-438

46. Noël P (1973) Sensory nerve conduction in the upper limbs at various stages of diabetic neuropathy. J Neurol Neuro Psychiatry 36: 786-796

47. Kimura J, Yamada T, Stevland NP (1979) Distal slowing of motor nerve conduction velocity in diabetic polyneuropathy. J Neurol Sci 42: 291-302

48. Jakobsen J, Sidenius P (1980) Decreased axonal transport of structural proteins in streptozotocin diabetic rats. J Clin Invest 66: 292-297

49. Tuomi T, Zimmet PZ, Rowley MJ, Serjeantson SW, Mackay IR (1993) Persisting antibodies to glutamic acid decarboxylase in type 1 (insulin-dependent) diabetes mellitus are not associated with neuropathy. Diabetologia 36: 685 (Letter)

50. Sundkvist G, Velloso LA, Kämpe O et al. (1994) Glutamic acid decarboxylase antibodies, autonomic nerve antibodies and autonomic neuropathy in diabetic patients. Diabetologia 37: 293-299

Note added in proof: A detailed description of the healthy controls can be found in the reference Hyllienmark L, Ludvigsson J, Brismar T. Normal values of nerve conduction in children and adolescents. Electroenceph clin Neurophysiol (in press). 